\title{
Next Level in Risk Management? Hedging and Trading Strategies of Volatility Derivatives Using VIX Futures
}

\author{
Ernst J. Fahling1 ${ }^{*}$, Elmar Steurer ${ }^{2}$, Tobias Schädler ${ }^{3}$, Adrian Volz ${ }^{1}$ \\ ${ }^{1}$ International School of Management, Frankfurt am Main, Germany \\ ${ }^{2}$ Hochschule Neu-Ulm, Neu-Ulm, Germany \\ ${ }^{3}$ Universidad Nacional de Educación a Distancia (UNED), Madrid, Spain \\ Email: *ernst.fahling@ism.de
}

How to cite this paper: Fahling, E. J., Steurer, E., Schädler, T., \& Volz, A. (2018). Next Level in Risk Management? Hedging and Trading Strategies of Volatility Derivatives Using VIX Futures. Journal of Financial Risk Management, 7, 442-459.

https://doi.org/10.4236/jfrm.2018.74024

Received: December 6, 2018

Accepted: December 26, 2018

Published: December 29, 2018

Copyright () 2018 by authors and Scientific Research Publishing Inc. This work is licensed under the Creative Commons Attribution-NonCommercial International License (CC BY-NC 4.0). http://creativecommons.org/licenses/by-nc/4.0/

\begin{abstract}
The paper analyses how volatility derivatives on the volatility index VIX can be used as trading and risk management tools for investors and traders. Volatility and the different types of volatility are discussed. It elaborates upon assumptions of option pricing models and specifies which complications accompany the determination of volatility. The weaknesses of the Black-Scholes-Merton model are illuminated and the difference between the model assumptions regarding volatility and market reality is identified. Using the skew- and term-curve-effect, the paper demonstrates how volatility behaves in reality towards other model parameters. In terms of pure volatility trading, the volatility derivatives are presented and analysed in terms of their merits and fields of application. Additionally, the stylized facts about volatility are considered. The paper shows how VIX futures and options can hedge equity portfolios and when they are superior to traditional hedging alternatives and compares the outcome of a VIX hedging strategy with a Buy \& Hold strategy of the S \& P 500 index over a time period of 20 years.
\end{abstract}

\section{Keywords}

Volatility Derivatives, Stylized Facts of Volatility, Comparison of Hedging Strategies, Trading Volatility

\section{Introduction}

Volatility as an indicator used to measure the fluctuating intensity of stock prices or rates in financial markets has gained significant attention in recent years. This cannot be traced back to a single event. In fact, it is more the result of 
a confluence of factors over the last few decades. Volatility has not only received more attention as a risk indicator, but become an interesting new asset class for investors. Events such as the Lehman Brothers collapse in 2008 and the European debt crisis mark a new era in the financial industry. Due to the reaction of the central banks by providing new instruments described as quantitative easing the development of the stock markets has been boosted mainly by fiscal policy and financial conditions since then. Thus, the financial system is more sensitive to announced changes of central bank policy resulting in unexpected large fluctuations.

This increased uncertainty has brought risk to the forefront when making investment decisions and increased the demand for hedging instruments as investors sought protection against an increasing level of exposure. The interest in trading derivatives, whose value derives from the value of other basic underlying variables such as stocks, bonds or indices has increased significantly in recent years. The interest in derivatives goes hand in hand with the interest in volatility. But why is this case?

Volatility is important because it is an essential parameter in every option pricing model. A trade with options is also a trade on the volatility of the underlying security. As a result of this, volatility trading is part of every single option trading strategy. It is important to note that there is no uniform consensus on the exact definition of volatility. A full understanding of volatility and its impact on the option price requires specification of all types of volatility.

Before the first volatility-based instruments entered the market, investments in volatility were only possible through a standard options portfolio. These portfolios were disadvantaged because they had to be hedged delta-neutral, i.e. the portfolio had to be made independent from price changes of the underlying security. Furthermore, it required a constant alignment, known as dynamic hedging. This hedging process was both time consuming and expensive, but it was the only alternative by that time to directly trade volatility.

Volatility trading revolutionized with the introduction of the first volatility-based index VIX in 1993 by the Chicago Board Options Exchange and the creation of instruments that had the index as underlying. New volatility instruments based on the index continue to be constructed. They form a new market segment for both retail, and institutional investors.

\section{The Volatility Assumption of Option Pricing Models}

\subsection{Parameter Volatility in the Black-Scholes-Merton Option Pricing Model}

Multiple model approaches for the valuation of financial options have been established. However, merely equilibrium models that imply certain hypotheses regarding the price development of the underlying instruments have achieved greater practical significance. Within the group of equilibrium models, the group of complete equilibrium models dominates in terms of application. Two models 
in particular from this group occupy a prominent position.

On the one hand, the Black-Scholes-Merton Model (B/S model) developed in 1973 by the American economists Black and Scholes (1973). On the other hand, the Binomial Option Pricing Model (BOPM) developed by Cox, Ross, and Rubinstein (1979) in 1979 that contains the B/S model as an edge case. Figure 1 illustrates the classification of the two models mentioned into the theoretical framework of option pricing models (Steiner, Bruns, \& Stöckl, 2012). Due to the frequency of its application in practice and its worldwide popularity, this work mainly refers to the Black-Scholes-Merton model (B/S model).

Volatility for different options, in option pricing theory, is considered constant - regardless of the strike price (or exercise price) and the remaining time-to-expiration. In practice, however, volatility behaves differently. Implied volatilities are exposed to a multitude of dynamic influencing factors that are interlinked. These factors include supply and demand, risk affinity, liquidity, as well as actions of the market participants. The market participants' expectations regarding future volatilities can be seen as the most important factor (Hilpold \& Kaiser, 2010).

The use of a traditional theoretical pricing model, such as the Black-ScholesMerton model, is undoubtedly associated with real problems. These problems result from the assumptions made by the pricing model. Reality shows that

- capital markets are not perfect,

- stock prices do not constantly follow a stochastic process with continuous variables in continuous time (a diffusion process),

- volatility does not have to remain constant, instead, it may fluctuate over an option's lifespan, and

- the real world does not have to resemble a lognormal distribution.

Considering all these weaknesses, there is a question whether theoretical pricing models provide traders with any practical value at all. However, traders have found that the use of a pricing model, even an imperfect one is nonetheless better than not using a model at all.

Traders who are trying to compensate for a pricing model's weaknesses may assume that the market uses the same model as themselves. Therefore, they then merely have to find out how the market deals with the model's weaknesses and apply the same for their case. This procedure is comparable to computing implied volatility. The implied volatility calculation assumes that:

- everyone uses the same pricing model,

- the option price is known, and

- everyone agrees on every input parameter, except volatility.

Thanks to these assumptions, it is possible to determine the volatility that the marketplace is implying via the option's market price to the underlying contract. The same general approach can be applied in modified form to the weaknesses in the pricing model (Natenberg, 2015).

Using the Black-Scholes model, an option's theoretical value over an option's lifespan depends exclusively on the volatility of the underlying contract, assuming 


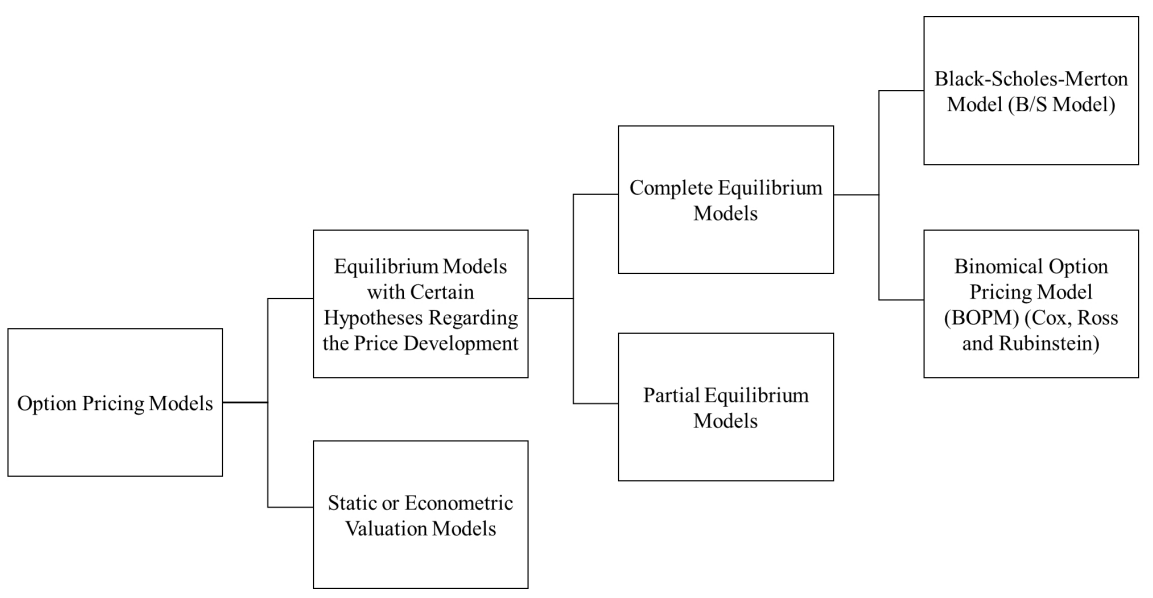

Figure 1. Classification of option pricing models.

the input parameters: underlying price, strike price, time-to-expiration and interest rate are known. Before expiration, traders will not know what the volatility of the underlying is. On the expiration date, it becomes possible to look back in time and calculate the historical volatility.

In a perfect Black-Scholes world, it does not make sense to have a different implied volatility for every single strike price. This is because all options (whether calls or puts) have the exact same index as the underlying. The purchase of underpriced options and the sale of overpriced options would ultimately cause every option to have the same IV, if the market's activity were a result of everyone's belief in the effectiveness of the Black-Scholes-Merton model. However, this almost never takes place in any market (Natenberg, 2015).

\subsection{Parameter Implied Volatility}

Among the parameters needed for the Black-Scholes-Merton valuation formulas, one cannot be directly observed: the volatility of the share price. Chapter 2 explained how share price volatility can be estimated using historical stock prices or returns. However, in reality, traders usually operate with implied volatilities. These are the volatilities included in the observed option prices on the market. Implied volatilities are used to monitor the market opinion on the volatility of a particular share. Whereas historical volatilities are calculated retroactively, i.e. on the basis of past prices, implied volatilities look to the future. Traders frequently substitute implied volatility for the option's price. This is very practical since the implied volatility usually fluctuates less than the option's price in the normal case. Relationship Between Implied Volatility and Other B/S Parameters Traders using a theoretical pricing model are exposed to two different risk types. First, the risk that the wrong inputs are used in the model. Second, the risk that the pricing model itself is erroneous due to either incorrect or unrealistic assumptions.

The first risk type is typically dealt with by traders by paying close attention to an option position's sensitivities (i.e., Delta, Gamma, Theta, Vega and Rho). 
In doing so, traders prepare to take protective action in case market conditions move against them. Even though each input poses a risk, special attention should be placed on volatility. This is because it represents the only input parameter that cannot be directly observed from the marketplace.

For speculative purposes, options are an excellent vehicle. However, this is not the main reason for the existence of the options market. Instead, its existence is fundamental to the primary economic purpose of options: a risk management tool for investors. Option contracts are used by hedgers as protection for their assets against adverse price movements. The demand for hedging via options goes hand in hand with the markets' risk perception. For instance, if the risk perception increases, the demand for this protection also increases. In this context, risk is expressed through volatility. It is thereby understood as the potential for large moves in either direction, as mentioned in Chapter 2. When the market expects higher volatility, the relative prices of options are forced upwards by increased demand for protective options.

In contrast, when the market anticipates lower volatility, greater supply (i.e. selling of options) forces option prices downwards.

\subsection{Volatility Skew}

Traders are enabled by a multitude of platforms to solve for volatility values of various options within the same option class. Options of the same class have interrelated values. Even though several model parameters are shared among the different series within the same class, IV may vary for different options within the same class. This is referred to as the volatility skew. Two types of volatility skew can be distinguished: vertical skew and horizontal skew (volatility term structure) (Passarelli, 2012).

The distribution of an option's implied volatilities across different strike prices is generally referred to as volatility skew. Depending on the skew's shape, two variants can be distinguished: volatility smirk or volatility smile (Natenberg, 2015). Figure 2 shows the actual volatility smile observed on 2018-11-17 for SPX contracts expiring on 2018-11-30.

The volatility smile skew shape can be frequently observed in near-term stock options and options in the foreign exchange market. Volatility smile patterns indicate that demand is larger for options that are in-the-money or out-of-the-money. The volatility smirk, in contrast, has two subvariants: the forward skew and the reverse skew. Whereas the forward skew shape typically appears for options in the commodities market, the reverse skew shape usually occurs with longer-term stock options and index options. The IV for options in the reverse skew shape increases with lower strike prices and decreases with higher strikes prices. This, in turn, suggests that OTM calls and ITM puts are cheaper relative to ITM calls and OTM puts.

The IV for options in the forward skew shape, in contrast, decreases with lower strikes and increases with higher strikes. This suggests that ITM calls and 


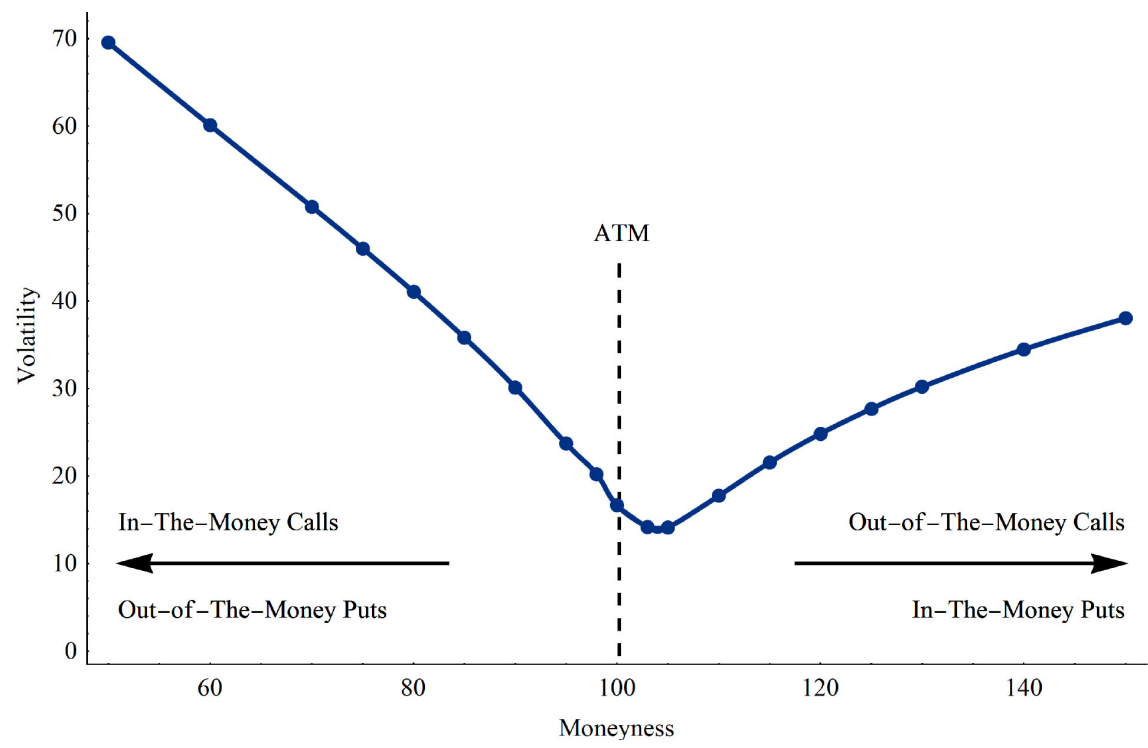

Figure 2. Volatility smile - SPX - Date: 2018-11-17 - Expiration Date: 2018-11-30.

OTM puts are in less demand relative to OTM calls and ITM puts (The Options Guide, 2017).

For the distribution of implied volatilities in the equity option market, one possible explanation has to do with the way in which option contracts are used as a hedging instrument.

As most traders in the equity market take long positions in stocks, they are more worried about an unexpected decline in share prices than about an unexpected increase. To protect a long underlying position (such as a stock), the two most widespread hedging strategies using options are the purchase of protective puts and the sale of covered calls.

If a stock investor chooses to buy a protective put, they are more in favour of choosing one at lower strike prices. Even though, an OTM put is cheaper than its ITM counterpart, it also offers less protection against downward movement.

If, however, the investor is so concerned about a downward movement that they require the protection of an ITM protective put, he should simply sell the stock instead (Natenberg, 2015).

If the stock investor chooses to sell a covered call, they will almost always favour choosing one at higher strike prices. This offers less protection compared to the sale of an ITM call, but the investor most likely holds the stock because he assumes an increase in the share price. The investor will want to participate in at least some of the upside profit potential, if the stock price increases as presumed. The stock will be rapidly called away, limiting any upside profit, if the investor has sold an ITM call and the share price increases.

In the equity option market, pressure tends to exist on both sides: buying pressure on the lower strike prices (the purchase of protective puts) and selling pressure on the higher strike prices (the sale of covered calls). This causes: IVs to increase with lower strike prices and IVs to decrease with higher strike prices. 
The resulting skew shape is referred to as reverse skew pattern and is common for options in the equity market.

The volatility skew transforms into an essential aid in managing risk and generating valuable theoretical values by handling it as an additional input into the theoretical pricing model. Furthermore, the skew analysis can build the foundation for a range of different option strategies (Natenberg, 2015).

\section{Trading Volatility}

Trading volatility as an asset class in its own right has a number of good reasons. For instance, investors may gain diversification by adding volatility to an equity portfolio as equity volatility is strongly negatively correlated with the equity price. Furthermore, investors may attain insurance against market crashes by holding volatility in an equity portfolio. This, in turn, is because volatility tends to rise significantly at such moments. They are mentioned here to give an impression of some features associated with volatility or volatility-based instruments. Whereas speculative traders may simply bet on future volatility, arbitrage traders and hedge funds may take positions on dissimilar volatilities of the same maturities. For trading pure volatility, instruments directly based on volatility indices have been established as popular instruments (Alexander, 2008).

Indirect instruments, however, reflect the trade on volatility via volatility indices. It should be noted that the application of indirect instruments is presented and analysed in this paper. These indirect instruments base on volatility indices.

The first volatility index, the CBOE Volatility Index (VIX index), was introduced in 1993 by the Chicago Board Options Exchange (CBOE). Initially, it was designed to measure the market's expectation of 30-day implied volatility by using ATM S \& P 100 index (OEX index) option prices. Shortly after its introduction, the VIX index transformed into the premier benchmark for U.S. equity market volatility. Nowadays, it is featured on a regular basis in a large number of leading financial publications and business news shows, where it is frequently referred to as the 'fear index' or 'market fear gauge': “The VIX is known as Wall Street's "fear gauge" because it tracks the expected swings in the S \& P 500 index using options contracts" (Sindreu 2018).

Ten years later in 2003, the CBOE, in collaboration with Goldman Sachs, updated the methodology of the VIX index. Their intention behind this update was not only to reflect a new way of measuring expected volatility (implied volatility), but above all to create a measure that can be used by financial theorists, risk managers and volatility traders in a similar manner. While the old VIX index was originally designed to measure the market's expectation of 30-day implied volatility by merely ATM S \& P 100 (OEX index) option prices, the new VIX index is designed to measure the market's expectation of 30-day implied volatility by averaging the weighted prices of S \& P 500 (SPX index) option prices, both calls and puts over a wide range of exercise prices. The input of the VIX index are the market prices of the call and put options on the S \& P 500 index with 
more than 23 days and less than 37 days until maturity.

This new methodology transformed the VIX index from a previously abstract concept into a practical standard for trading and hedging volatility by supplying a script for replicating volatility exposure with a portfolio of SPX index options.

In 2014, the CBOE upgraded the VIX index by incorporating series of SPX Weeklys (weekly options). Since their introduction weekly options have transformed into a very popular and actively traded risk management tool that are available on many indexes, equities, ETFs and ETNs. Through August 2014, SPX Weeklys averaged over a quarter of a million contracts traded per day and constituted about one-third of all SPX option contracts traded. The insertion of SPX weekly options allows the VIX index to be computed using S \& P 500 index option series, which most accurately correspond to the 30-day target timeframe for implied volatility that the VIX Index aims to reflect. The fact that the VIX index always reflects an interpolation of two points besides the S \& P 500 volatility term structure is ensured by using SPX option contracts with less than 37 days and more than 23 days to expiration (Chicago Board Options Exchange, 2014).

The first exchange-traded VIX futures contract was launched by the CBOE in March 2004 on its new all-electronic CBOE Futures Exchange (CFE). Two years later in February 2006, the CBOE introduced its next VIX-based product, VIX options. This represents the most successful new product in CBOE history. Combined trading activity in VIX futures and options has risen to a daily trading volume of over 800,000 contracts within merely 10 years since their launch (Chicago Board Options Exchange, 2014).

The inverse relationship between equity volatility and equity market returns is well documented and suggests a diversification benefit of incorporating volatility in an investment portfolio. VIX futures and options are both instruments that offer investors the possibility to obtain a pure volatility exposure in a single and efficient package.

A continuous, liquid and transparent market for VIX products is provided by the CBOE/CFE. VIX products are available to all types of investors, from the smallest retail trader to the largest institutional money managers and hedge funds. Besides the VIX index, the CBOE also computes several other volatility indices on equity indexes (Chicago Board Options Exchange, 2014). These indices diverge from the VIX index in either the underlying equity index and/or the observed timeframe for expected volatility (implied volatility) (Chicago Board Options Exchange, 2014).

\section{Trading and Hedging Strategies Using VIX Derivatives}

\subsection{Stylized Facts about Volatility}

This section examines how volatility actually behaves in practice. This represents essential knowledge when considering trading with VIX futures and options or volatility derivatives in general. Therefore, stylized facts about volatility must be 
examined (Sinclair, 2013). A stylized fact can be defined in the study of financial data represents a property that is strong enough to be accepted as universally valid.

Econometric studies have revealed considerable amounts of commonalities in financial time series of different assets. It was found that the fluctuations in asset prices share several significant statistical properties. These properties have become known as stylized facts.

It should be emphasized that the stylized facts described here basically represent generalities, which means they do not need to prove true in every individual case. Despite the loss of precision when using generalities, they are useful for spotting broad similarities. Many of the facts will be qualitative. It is extraordinarily complex to integrate all these properties into models of the underlying, let alone option pricing models. Therefore, the objective should not be to search for a pricing model that captures all these properties, but to use tweaks and fudges to integrate these facts into the use of the Black-Scholes-Merton formalism and the volatility estimation problem. Thus, for volatility traders, it is essential to know as much as possible about any fact that concerns volatility. Stylized facts show up following characteristics:

- "Volatility is not constant. It mean-reverts, clusters, and possesses long memory.

- In most markets, volatility and returns have a negative correlation. This effect is asymmetric: negative returns cause volatility to rise sharply while positive returns lead to a smaller drop in volatility. This effect occurs most prominently in equity markets.

- Volatility and volume have a strong positive relationship.

- The distribution of volatility is close to log-normal" (Sinclair, 2013: p. 36).

\subsection{Nonconstant Volatility (Volatility Clustering)}

The fact that volatility does not remain constant has been documented by several studies (Akgiray, 1989; Turner \& Weigel, 1992). The effect is uncomplicated to visually confirm and robust to the exact way volatility is estimated. Figure 3 illustrates the monthly 30-day close-to-close volatility of the S \& P 500 index (SPX) from 1990-01-31 to 2018-0-31. Therefore, it shows the historical fluctuation intensity of the SPX.

Two interesting properties can be observed. First, one can easily recognize that volatility does change over time, and second that it changes in specific ways, so called "volatility clusters". The phenomenon of volatility clusters appears to have been first noticed by Mandelbrot (1963). He claimed that "large changes tend to be followed by large changes ... and small changes tend to be followed by small changes" (Mandelbrot, 1963: p. 418). Significant autocorrelations are shown in particular by both squared returns and absolute returns (proxies for one-day volatility). Figure 4 and Figure 5 illustrate these autocorrelations for the SPX as a function of a range of lags. 


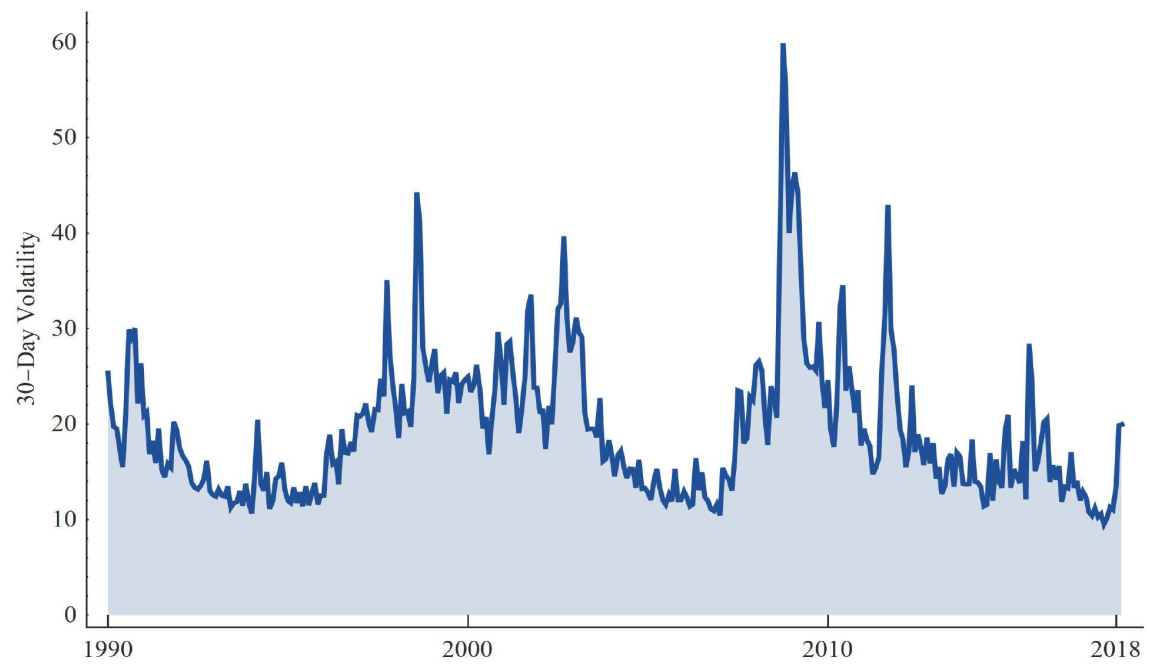

Figure 3. CBOE Volatility Index (VIX).

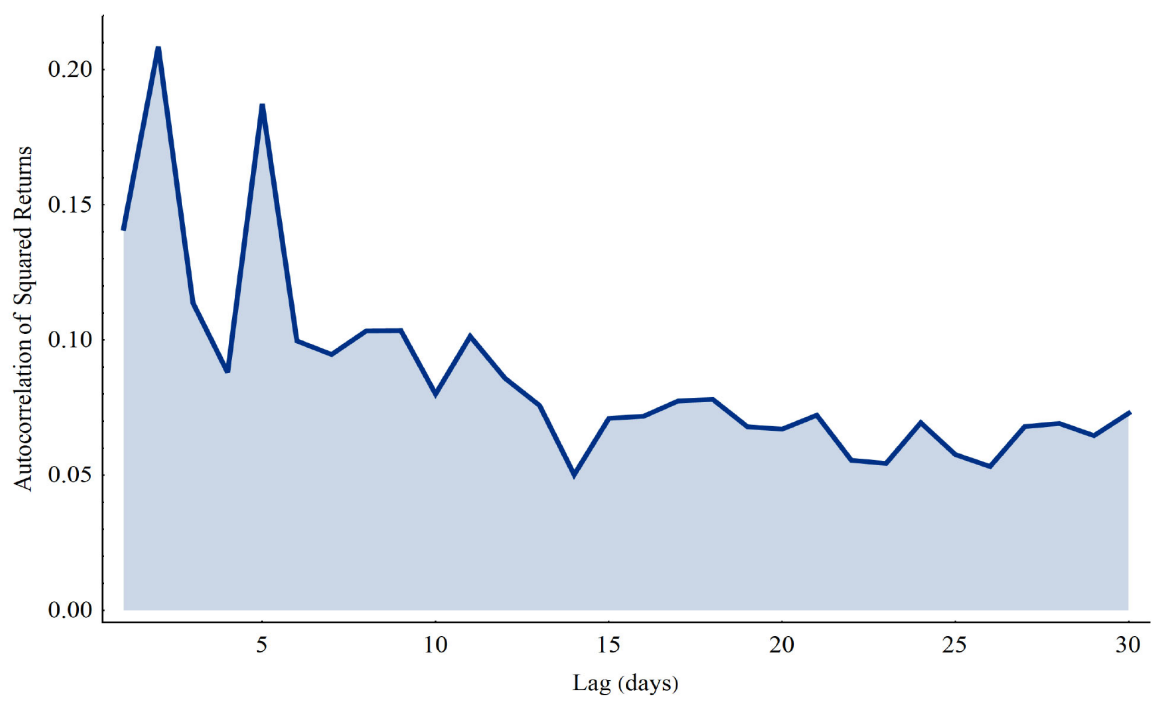

Figure 4. Autocorrelations for the daily squared log returns of the SPX from 1963-12-31 to $2018-05-31$.

Volatility clustering occurs independent of the underlying instrument. It has been observed across a variety of different assets, including indices, equities, commodities, and currencies (Taylor, 1986).

Clustering suggests that the current volatility level represents a good estimate for future volatility. Option traders have internalized the rule of thumb that states that tomorrow's level of volatility will be identical to today's level. They do not value how remarkable this piece of information is for their trading activities. Volatility clustering implies that volatility is relatively predictable. This represents a significant feature which the underlying price certainly does not have.

\subsection{Negative Correlation (Leverage Effect)}

Another important stylized fact to be mentioned is the inverse relationship between equity prices and volatility. This persistent effect indicates that volatility 


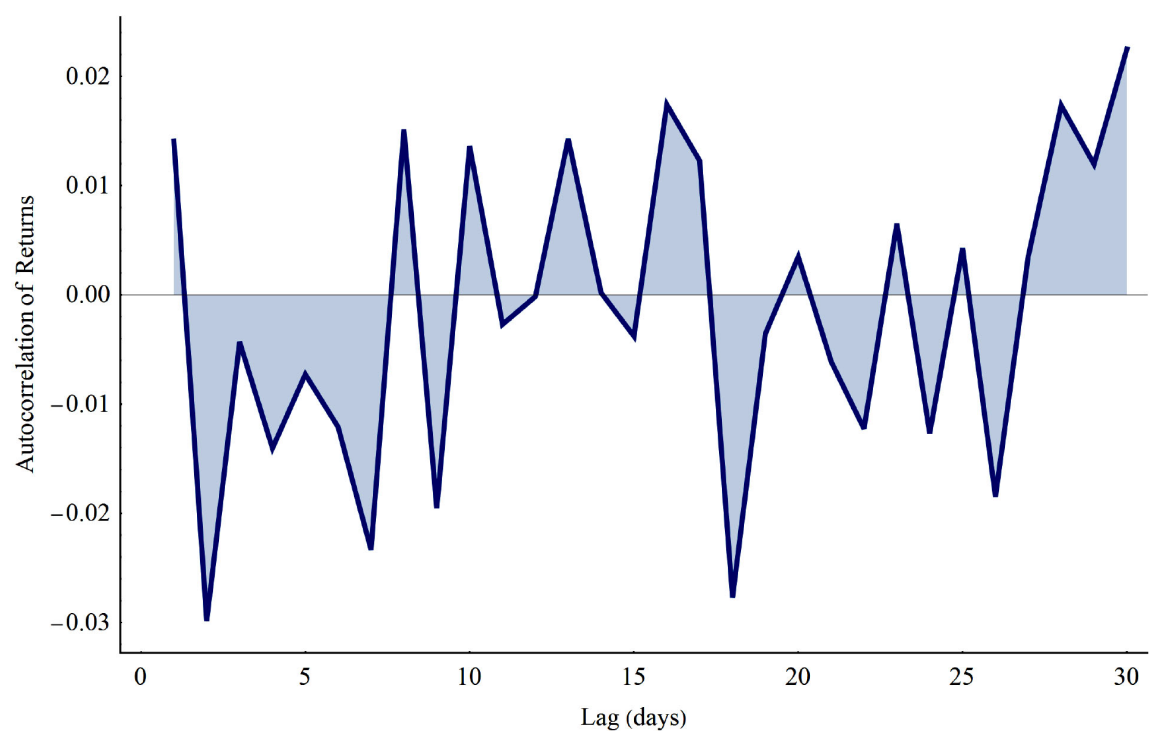

Figure 5. Autocorrelations for the daily log returns of the SPX from 1963-12-31 to 2018-05-31.

tends to rise when the price of the underlying drops. It can be explained by the 'leverage effect' companies are exposed to and thus is as an explanation for the effect in stocks. A drop in the share price, in the case of a corporation that has not issued any debt, triggers an increase in the company's financial leverage. This, in turn, increases its risk and leads to higher volatility.

Even though, this explanation appears plausible, it does not seem to explain the effect in practice (Figlewski \& Wang, 2001). This does not represent a new observation, various economists have remarked upon it (Black, 1976; Christie, 1982). Ever since, it has been the subject of a large number of published studies. While this effect is very common in particular for equity indices, it is also true for a broad variety of other assets, such as individual equities, bonds, and several commodities. It appears to be a significant property of any asset, in which investors put their money and therefore have a positive expected return. For instance, it generally does not apply to currencies (Sinclair 2013). Figure 6 shows the SPX plotted against its 30-day IV (VIX index). The inverse relationship between IV (VIX) and the underlying price (SPX) is particularly visible during stock market crashes and longer lasting periods of downwards corrections. For the time series ranging from 1990-01-02 to 2018-06-29 the correlation between the daily log returns of the SPX and the daily returns of the VIX is -0.787 .

\subsection{Volume and Volatility}

The next-to-last stylized fact to be mentioned deals with the relation between trading volume and volatility. Trading volume is strongly correlated with every single measure of volatility. It is relatively complex to establish the causality in their relationship. Good arguments can be made for both sides, for volatility encouraging investors to trade and therefore causing an increase in trading volume, as well as for trading volume moving the price of the underlying and 


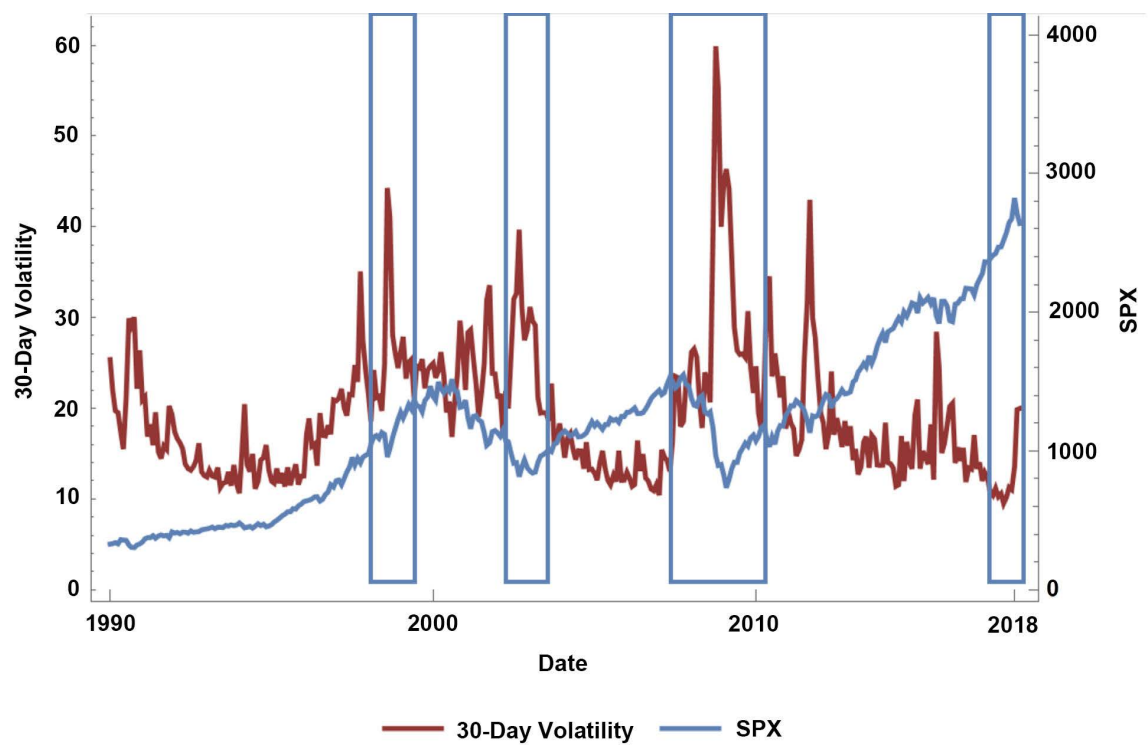

Figure 6. Negative correlation between SPX and VIX (monthly basis).

therefore causing volatility. Nonetheless, the relationship between both variables is robust and lasts over all timeframes (Tauchen \& Pitts, 1983; Lee \& Rui, 2002; Sinclair, 2013: p. 43f.). However, when it comes to an empirical evidence this stylized fact cannot be proven clearly. Figure 7 shows the relationship by plotting daily volume against the daily range and daily absolute returns for the SPX from 2011-04-01 to 2016-03-31. The indefinite and vague visual impression is confirmed by the very low coefficient of determination of a linear regression as of 0.000622 . This evidence indicates strongly that a relation between volume and volatility is not self-evident, which contrasts the empirical findings mentioned above. Thus, this stylized fact should be assessed critically - obviously it depends largely on the time period chosen.

\subsection{Volatility Distribution}

The last stylized fact concerns the distribution of volatility. This has been suggested as log-normal by several studies (Andersen, Bollerslev, Diebold, \& Ebens, 2001; Cizeau, Liu, Meyer, Peng, \& Stanley, 1997). However, there is at least one study which has indicated that the distribution's tail would be better characterized as a power law (Liu et al., 1999). The particular distribution is possibly irrelevant. The significant fact is that the distribution is strongly skewed to the right with a lot more periods of high volatility than one would expect if the distribution was normally distributed. This is apparent in Figure 8, which shows the distribution of 30-day volatility for the S \& P 500 index from 1990-01-02 to 2018-06-29. In other words, this implies that volatility spends much more time in low states than it spends in high states.

Furthermore, the distribution of volatility diverges significantly in bull and bear markets. This becomes apparent in the following example. From 1990 to 2011 if the SPX was higher than its 200-day moving average, then the median 


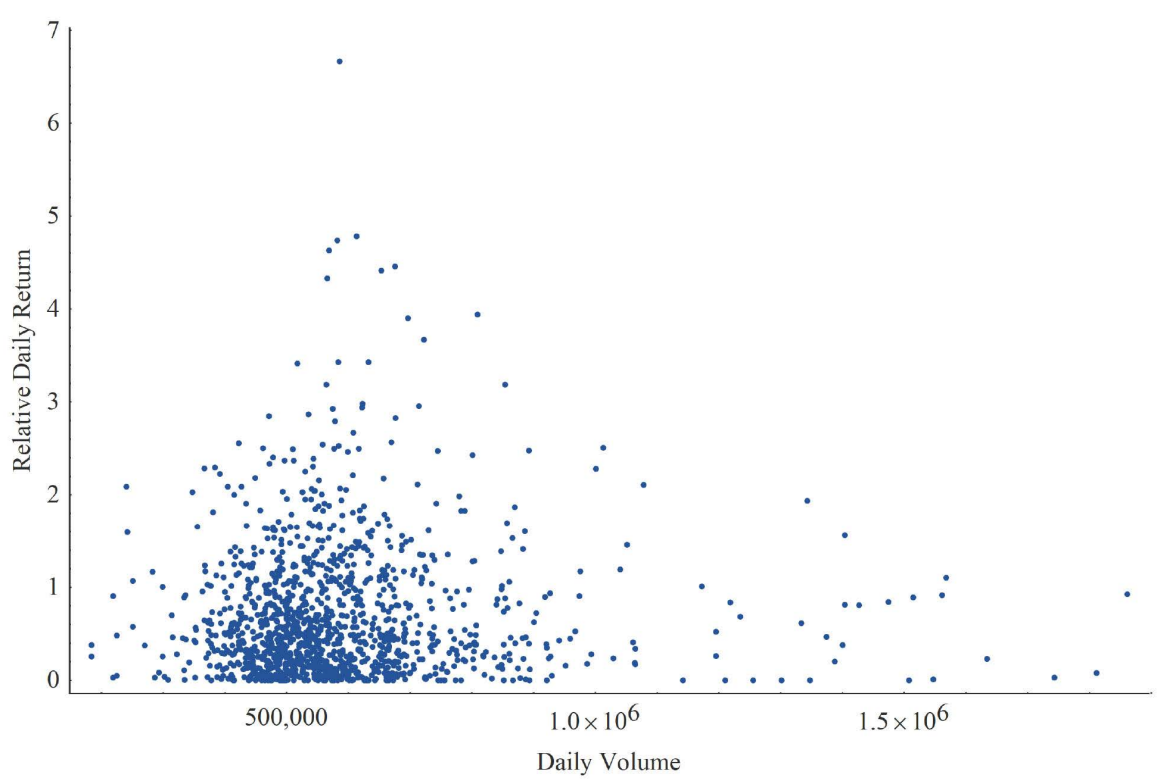

Figure 7. Relative daily price changes of S \& P 500 index against daily volume.

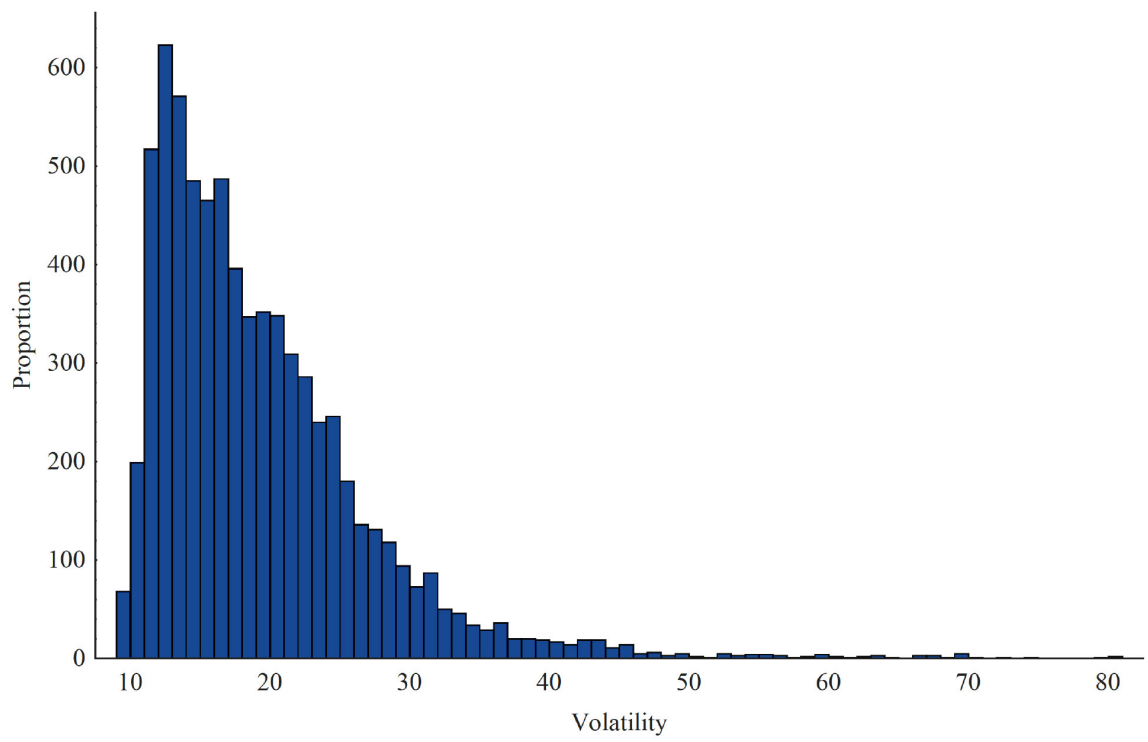

Figure 8. VIX distribution: 1990-01-02 to 2018-06-29.

30-day volatility was $12.1 \%$. If, however, the SPX was lower than its 200-day moving average, then the median 30-day volatility was $21.6 \%$ (Sinclair, 2013: p. 45).

This observation is robust in relation to the way volatility is measured and the length of the moving average used to determine whether the underlying market is in a bull or bear phase. It is comprehensible that as volatility trader, one needs to fully understand and master volatility. This is correct regardless of the level of quantitative analysis one plans to use Sinclair: "Each individual product will have certain quirks and nuances, but all volatilities have a number of common features. 
- Volatility clusters.

- Volatility mean reverts.

- Volatility tends to increase as the underlying price declines.

- Volatility and volume are highly correlated.

- Volatility is approximately log-normally distributed." (Sinclair, 2013: p. 47)

\section{Empirical Study on Combined Portfolio Performance}

In this chapter empirical findings of the success of indirect instruments to trade volatility are presented. It will be shown how a consistent mix of both portfolios, i.e. the pure long stocks portfolio and the VIX futures portfolio, would have performed in the past in two different time periods.

Firstly, the analysis undertaken by Rhoads (2011) shows the monthly performance for a combined portfolio with a $90 \%$ exposure to the S \& P 500 index portfolio and a $10 \%$ exposure to the VIX futures portfolio. Important to note is, that the analysis focuses on the years 2007 until 2010 which was the area of the financial crisis. In that time period the combined portfolio clearly outperformed the pure SPX portfolio in the years 2007 and 2008, while it slightly underperforms in the latter two years. This relative performance can be ascribed to the volatility trend during the respective period. There has been an uptrend in volatility through 2007 and 2008, while there was basically a downward to flat volatility trend in 2009 and 2010.

Secondly, an own further long-term performance study of a SPX portfolio hedged by VIX derivatives is analysed. It is analysed, how the full protection of the SPX via corresponding one-month ATM European put options compares to the index itself over the long run ranging from 1990-01-31 to 2018-03-30. Albeit while tests of put options around the volatility smile are not conducted it is possible to relate the results to them. Overall the study concludes that by hedging the index as described, $80 \%$ of the gains of the SPX with distributed dividends considered are eliminated by simultaneously raising volatility significantly within the sample period.

For the study the well-known Black-Scholes partial differential equation for European put options (Black \& Scholes, 1973; Davis, 2010) with V as V(S,t) the option value, $S$ is the price and $\sigma$ the volatility of the underlying asset, $t$ as time to maturity and $\mathrm{k}$ as the strike price is extended for continuously paying dividends (d) and applied as follows:

$$
\frac{\partial V}{\partial t}+\frac{1}{2} \sigma^{2} S^{2} \frac{\partial^{2} V}{\partial S^{2}}+(r-d) S \frac{\partial V}{\partial S}-r V=0 \text { with } V=\max (k-S, 0)
$$

Solving this equation for the initial boundary value problem leads to the homogenous linear Black-Scholes formula. Dividends paid from the SPX are accounted for on a monthly basis without being reinvested.

Put option positions are rolled over on the last trading day of each month onto the last day of the following months based on the calendar of the New York Stock Exchange (NYSE). The time to maturity measured in days of each option 
is calculated until the last trading day of the following month. The implied volatility refers to ATM VIX values.

For the sample period before 2007-12-05 the volatility is estimated on basis of VIX values adjusted for differences to ATM VIX values due to the volatility smile. The adjustments are determined by a linear regression model which parameters are calculated through the ordinary least squares (OLS) method. For the fitted model

$$
-2.16777+0.976595 x
$$

the F-Statistic of 157.997 corresponds to the P-Value of 0 and a coefficient of determination of $98.3 \%$. Thus, the explanatory power of that model can be regarded as tremendously well. Figure 9 shows the relationship between the VIX versus the ATM VIX and the fitted model on a daily basis from 2007-12-05 to 2018-06-26. Data for daily ATM VIX and VIX values are derived from Thomson Reuters Datastream.

Monthly data used for the model derived from Thomson Reuters Datastream are the SPX, dividends of the SPX, the ICE Benchmark Administration (IBA) and the United States Dollar Interbank LIBOR 1 Month as the risk-free rate. Daily VIX and ATM VIX data is as well derived from Thomson Reuters Datastream. Figure 10 shows the performance effects of hedging the SPX including distributed dividends with one-month ATM European put options over the period from 1990-01-31 to 2018-03-30. Over the same period Figure 11 illustrates the premiums paid and gains received from the hedging strategy.

The empirical result is, that the compound annual growth rate (CAGR) of $8.5 \%$ of the unhedged SPX is reduced to $3.9 \%$ by applying the evaluated volatility based hedging strategy. On the other hand, the annual volatility raises from $12.0 \%$ to $17.7 \%$. In nominal terms $80 \%$ of the gains of the SPX with distributed dividends are eliminated due to the negative cash balance of the option strategy.

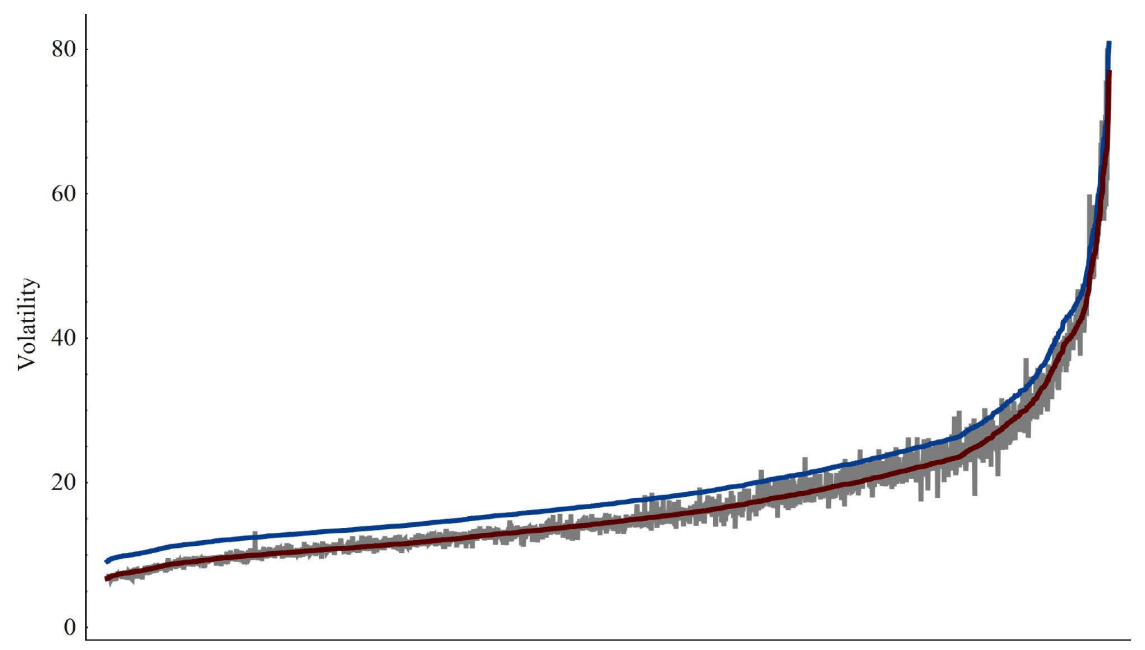

Figure 9. Daily VIX values (blue line) sorted ascending versus corresponding ATM VIX values (grey line) and the linear regression model (red line). 


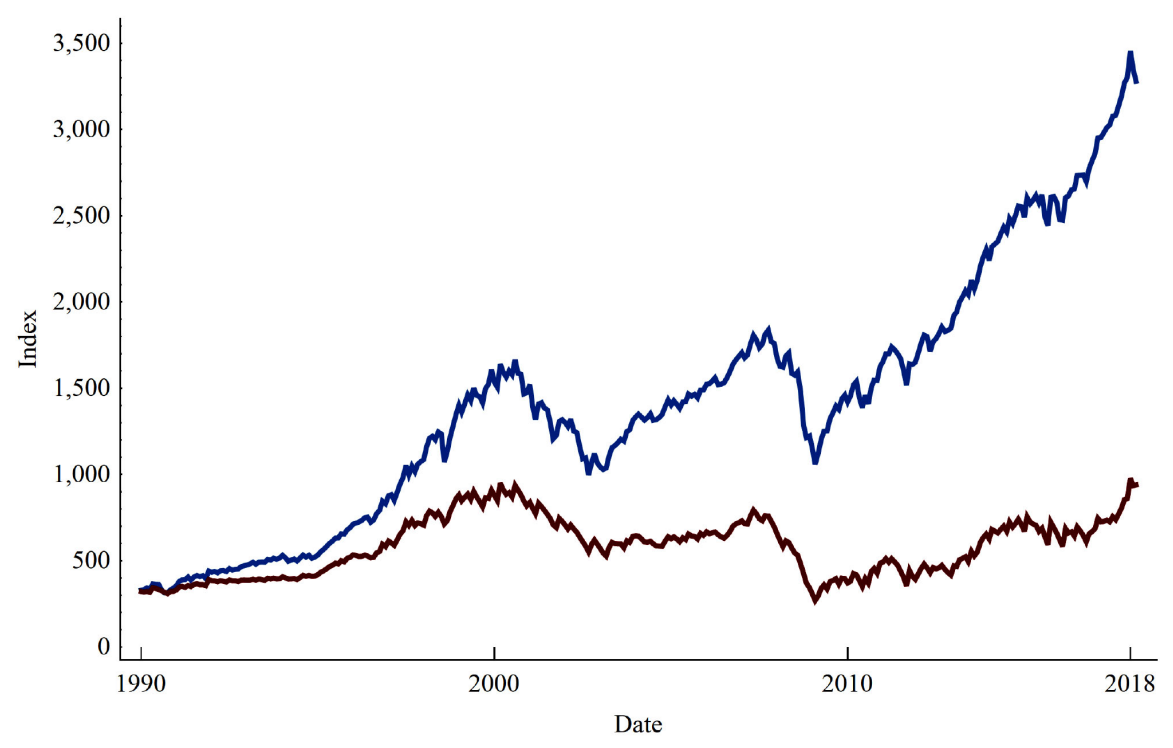

Figure 10. Time series of the SPX including dividends (blue line) and the hedged SPX including dividends (red line).

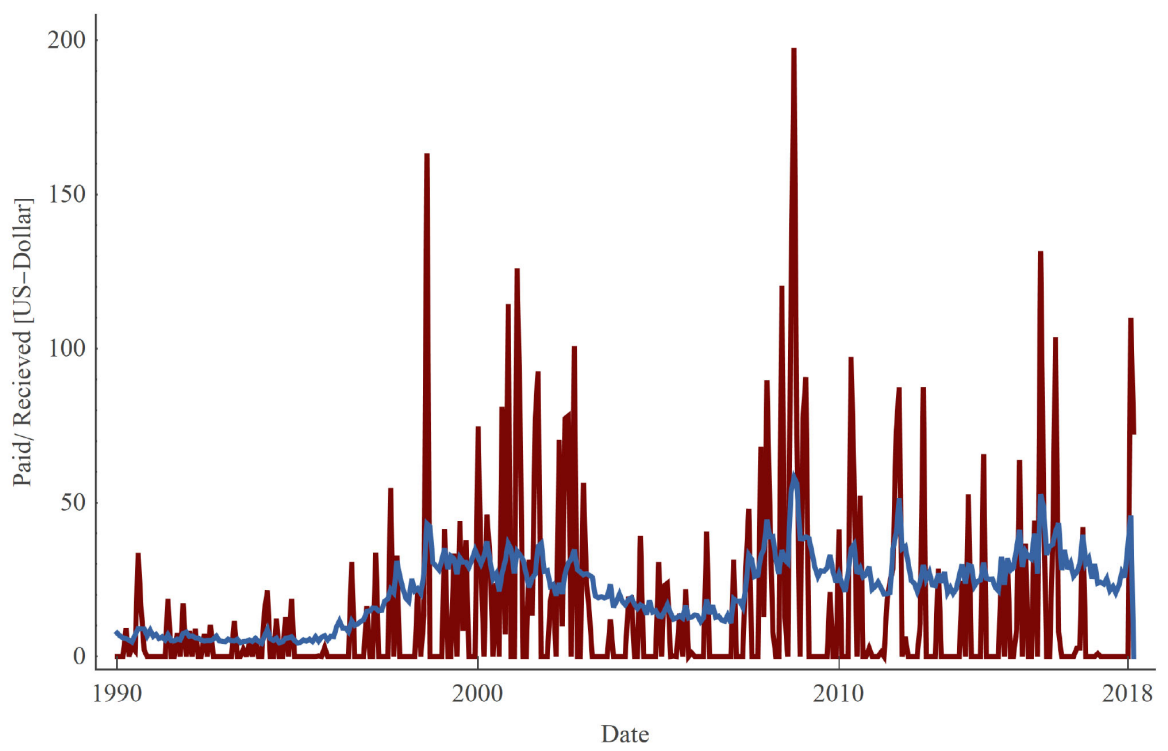

Figure 11. Premiums paid (blue line) and respective gains received (red line) over the sample period.

\section{Conclusion}

Volatility as an asset class and trading tool continues to be a rapidly growing and developing area in the financial industry. Trading volatility as an asset class in its own right has been established for a number of reasons. Investors may obtain excellent diversification by adding volatility to their portfolios. This is not least attributable to its negative correlation with equity market returns. Investors may also attain disaster insurance against market crashes by holding volatility in an equity portfolio as it tends to increase significantly at such times. These features, among others, make investments in volatility an ideal instrument for hedging 
purposes. These hypotheses are supported by the studies referred to in this work. Moreover, its application is not limited to hedgers only.

Volatility properties, such as mean reversion or volatility clustering, allow investors to make better predictions on the long-term future development of volatility. Volatility products are a topic with plenty of room for future research. Many volatility products, such as options and futures on the VIX, have not been traded for a very long time, but have nonetheless recorded a significant increase in average trading volume. Especially in the case of newly introduced volatility products, such as certificates on volatility indices, it is necessary to examine what the long-term yield opportunities look like and in which areas their application might be worthwhile.

The main purpose of this study was to gather an empirical insight how the long-term performance of the application of volatility derivatives to hedge a long position in the S \& P 500 index will result in. The empirical findings clearly show that over the last 20 years a protective put strategy for the S \& P 500 index would have contributed to a significant underperformance against a buy \& hold strategy of the S \& P 500 Index. With this empirical finding in mind, the applications of volatility derivatives obviously mainly make sense from a tactical market perspective rather than a strategic one.

\section{Conflicts of Interest}

The authors declare no conflicts of interest regarding the publication of this paper.

\section{References}

Akgiray, V. (1989). Conditional Heteroscedasticity in Time Series of Stock Returns. The Journal of Business, 62, 55-80. https://doi.org/10.1086/296451

Alexander, C. (2008). Pricing, Hedging and Trading Financial Instruments. Chichester: Wiley.

Andersen, T. G., Bollerslev, T., Diebold, F. X., \& Ebens, H. (2001). The Distribution of Realized Stock Return Volatility. Journal of Financial Economics, 61, 43-76. https://doi.org/10.1016/S0304-405X(01)00055-1

Black, F. (1976). Studies of Stock Price Volatility Changes. In Proceedings of the 1976 Meeting of the Business and Economical Statistics Section (pp. 177-181). Washington, DC: American Statistical Association.

Black, F., \& Scholes, M. (1973). The Pricing of Options and Corporate Liabilities. Journal of Political Economy, 81, 637-654. https://doi.org/10.1086/260062

Chicago Board Options Exchange (2014). White Paper: Cboe Volatility Index. https://www.cboe.com/micro/vix/vixwhite.pdf

Christie, A. (1982). The Stochastic Behavior of Common Stock Variances. Journal of Financial Economics, 10, 407-432. https://doi.org/10.1016/0304-405X(82)90018-6

Cizeau, P., Liu, Y., Meyer, M., Peng, C.-K., \& Stanley, H. E. (1997). Volatility Distribution in the S \& P 500 Stock Index. Physica A: Statistical Mechanics and Its Applications, 245, 441-445. https://doi.org/10.1016/S0378-4371(97)00417-2

Cox, J. C., Ross, S. A., \& Rubinstein, M. (1979). Option Pricing. Journal of Financial 
Economics, 7, 229-263. https://doi.org/10.1016/0304-405X(79)90015-1

Davis, M. H. (2010). Black-Scholes Formula. In R. Cont (Ed.), Encyclopaedia of Quantitative Finance (pp. 199-207). Chichester: Wiley. https://doi.org/10.1002/9780470061602.eqf05004

Figlewski, S., \& Wang, X. (2001). Is the "Leverage Effect" a Leverage Effect? SSRN Electronic Journal. https://doi.org/10.2139/ssrn.256109

Hilpold, C., \& Kaiser, D. G. (2010). Innovative Investmentstrategien. Wiesbaden: Gabler. https://doi.org/10.1007/978-3-8349-8749-5

Lee, B.-S., \& Rui, O. M. (2002). The Dynamic Relationship between Stock Returns and Trading Volume. Journal of Banking \& Finance, 26, 51-78. https://doi.org/10.1016/S0378-4266(00)00173-4

Liu, Y., Gopikrishnan, P., Cizeau, P., Meyer, M., Peng, C. K., \& Stanley, H. E. (1999). Statistical Properties of the Volatility of Price Fluctuations. Physical Review E, 60, 1390-1400. https://doi.org/10.1103/PhysRevE.60.1390

Mandelbrot, B. (1963). The Variation of Certain Speculative Prices. The Journal of Business, 36, 394-419. https://doi.org/10.1086/294632

Natenberg, S. (2015). Option Volatility and Pricing (2nd ed.). New York: McGraw-Hill Education.

Passarelli, D. (2012). Trading Options Greeks (2nd ed.). New York: Bloomberg Press. https://doi.org/10.1002/9781118531846

Rhoads, R. (2011). Trading VIX Derivatives. Hoboken, NJ: Wiley.

Sinclair, E. (2013). Volatility Trading (2nd ed.). Hoboken, NJ: Wiley.

Sindreu, J. (2018). Wall Street's Fear Gauge Flashes Green Again. Wall Street Journal. https://www.wsj.com/articles/wall-streets-fear-gauge-flashes-green-again-1539870354

Steiner, M., Bruns, C., \& Stöckl, S. (2012). Wertpapiermanagement (10th ed.). Stuttgart: Schäffer-Poeschel.

Tauchen, G. E., \& Pitts, M. (1983). The Price Variability-Volume Relationship on Speculative Markets. Econometrica, 51, 485-505. https://doi.org/10.2307/1912002

Taylor, S. (1986). Modelling Financial Time Series. Chichester: Wiley.

The Options Guide (2017). Volatility Smiles \& Smirks. http://www.theoptionsguide.com/volatility-smile.aspx

Turner, A. L., \& Weigel, E. J. (1992). Daily Stock Market Volatility. Management Science, 38, 1586-1609. https://doi.org/10.1287/mnsc.38.11.1586 